

\title{
DA VIOLÊNCIA DE GÊNERO ÀS VIOLÊNCIAS INSTITUCIONAIS: FALANDO SOBRE VIOLÊNCIA AOS PROFISSIONAIS DE UMA DP DE FLORIANÓPOLIS
}

\author{
Fernando Luiz Salgado da Silva \\ Acadêmico do curso de psicologia da UFSC \\ Marina Gomes Coelho de Sousa \\ Acadêmica do curso de psicologia da UFSC \\ Arthur Grimm Cabral \\ Mestrando do programa de pós-graduação em Psicologia da UFSC \\ Dra. Maria Juracy Filgueiras Toneli \\ Professora do Departamento de Psicologia da UFSC (Coordenadora) \\ juracy@cfh.ufsc.br
}

\section{Resumo}

Este trabalho propõe-se a relatar uma intervenção realizada junto a profissionais na Delegacia da Mulher ( $6^{\text {a }}$ delegacia de polícia) do município de Florianópolis. A intervenção - que inicialmente pretendia discutir gênero e violência com os funcionários, para a implantação de um grupo de atendimento a homens autores de violência na delegacia - produziu outros efeitos sobre a instituição, constituindo-se assim, num espaço de estranhamento do seu trabalho, marcado por um campo de forças bastante instituídas. Utiliza-se, nesse artigo, conceitos advindos da análise institucional, colocando em análise o campo de forças e instituições que atravessam o estabelecimento em questão.

Palavras-chave: Violência. Instituição. Sobreimplicação profissional. Delegacia de polícia.

\section{FROM GENUS VIOLENCE TO INSTITUTIONAL VIOLENCE: TAKING ABOUT} VIOLENCE WITH THE PROFESSIONALS/STAFF FROM DP IN FLORIANOPOLIS

\begin{abstract}
These job recommend to expound a intervention done together with the Woman Police Station (6th Precinct) from the municipalite of Florianopolis. The intervention that inicially had the intention to discuss gender and violence between the employees. To implemment a support group to the man whom are the authores of such violence at the station to create different effects in the institution. Whereby in a strange working space deceitful by a vigour


field very intuitive. We use in the article concepts that comes from institutional analyses. Where we put these analyses of the vigours fields and the institution that cross these establishments.

Key words: Violence. Institutions. Professions under implementation. Police station.

\section{Introdução}

A partir da aprovação da lei 11.340/2006 - Lei Maria da Penha -, o Brasil passou a ser o $18^{\circ}$ país da América Latina a possuir, em sua legislação, uma lei específica para casos relacionados às diferentes formas de violência doméstica contra as mulheres: física, psicológica, sexual, patrimonial e moral.

A lei surge para romper a forma como esses tipos de violência eram entendidos, até então, no Código Pena. Eles deixam de ser "crimes de menor potencial ofensivo" e passam a implicar o aumento da pena. A lei Maria da Penha erradica a possibilidade de penas alternativas e viabiliza a prisão em flagrante do agressor. Essa Lei torna-se pioneira também em outro aspecto: pela primeira vez a "violência baseada em gênero" - definida como aquela que se adota contra as mulheres devido à especificidade de seu sexo - tem sua existência reconhecida e explicitada no plano legal.

Frente ao objetivo de "Erradicar todas as formas de violência contra as mulheres" (Lei Maria da Penha), a lei depara-se com barreiras outras além daquelas que resistem no plano legal. Por exemplo, no plano das normas culturais, aquilo que "governa a inteligibilidade social da ação" (BUTLER, 2004, p. 41) encontramos toda sorte de discursos e crenças (frequentemente implícitas) que operam na regulação da forma como os homens e mulheres devem pensar, sentir, desejar e agir, sustentando e "normalizando" a prática da violência contra as mulheres.

O parágrafo VII do Art. $8^{\circ}$ prevê "a capacitação permanente das Polícias Civil e Militar, da Guarda Municipal, do Corpo de Bombeiros e dos profissionais pertencentes aos órgãos e às áreas enunciados no inciso I quanto às questões de gênero e de raça ou etnia" como um dos aspectos chave para a erradicação de todo tipo de violência contra a mulher, entendendo que a lei tornar-se-ia incipiente caso tais instâncias permaneçam - cientes ou não de fazê-lo - reproduzindo crenças sexistas, misóginas e racistas no exercício de seu trabalho.

Neste ensejo, foi elaborado o projeto de extensão "Capacitação de profissionais da $6^{\mathrm{a}}$ DP de Florianópolis e implantação de grupos de homens autores de violência contra a 
mulher", no intuito de promover, junto aos profissionais desta delegacia, espaços de reflexão, visando desnaturalizar preconceitos possivelmente arraigados acerca da violência contra a mulher e a desigualdade de gênero, compreendendo também a construção social das masculinidades que produzem a subjetividade dos autores de violência.

Entretanto, mais do que um espaço didático - modelo relacional que posiciona os coordenadores do grupo num espaço de "saber" e seus membros em um lugar de "não saber" - o grupo reflexivo assumiu uma autonomia inesperada, encaminhando a intervenção para uma reflexão acerca das relações institucionais que recortavam o trabalho na delegacia.

Cabe aqui esclarecer a noção de instituição que atravessa nosso trabalho. Trata-se da análise institucional francesa, que diferencia "instituição" de estabelecimento, local geográfico. Instituição é toda e qualquer relação que se caracteriza pela naturalização de práticas concretas ligadas à submissão, exploração, disciplinarização, etc; práticas instituídas e percebidas como naturais, eternas e necessárias. Entretanto, além dessas forças instituídas, toda instituição também supõe forças instituintes, o que permite sua transformação e, mesmo, extinção.

\section{Material e Métodos}

O grupo de discussão, realizado com profissionais da Delegacia da Mulher, contou com a adesão voluntária de profissionais, com predominância da participação de psicólogas e psicólogos. O tempo de trabalho na delegacia dos participantes era bastante heterogêneo: alguns estavam lá há 20 anos, outros haviam recentemente iniciado seu trabalho.

A periodicidade de cada encontro era quinzenal, tendo a duração de cerca de três horas. As atividades funcionavam na forma de oficinas lúdicas (filmes, colagens, compartilhar músicas, etc.) relacionadas à temática norteadora de cada atividade. Antes de cada encontro, a equipe se reunia para decidir qual seria a atividade a ser realizada. Ainda que, muitas vezes, as oficinas caminharam por outras direções, surgindo questões relacionadas ao cotidiano de trabalho da delegacia, não obstante, este tópico será abordado em outro momento do artigo.

\section{Resultados e Análise}

Logo no primeiro encontro, a partir de uma fala do grupo afirmando "nós estamos cansados de capacitação" (sic), percebemos que teríamos que repensar nosso projeto. Afinal, não éramos meros aplicadores de conhecimento, mas, sim, pesquisadores atentos à 
processualidade e complexidade do seu campo, atentos aos movimentos que sinalizavam a necessidade de questionar a lógica da intervenção dos capacitadores, bem como a eficácia de suas metodologias. Estariam eles preparados para trabalhar com homens autores de violência sem por em análise as violências do dia-a-dia destes profissionais? Estariam "capacitados" com a transmissão de conhecimentos adquiridos em algumas reuniões? Essa fala nos faz pensar sobre uma série de questões acerca do trabalho daqueles que adentram nas instituições para transmitir um conhecimento técnico sem a menor análise de implicações do campo.

Durante uma oficina, pré-planejada para trabalhar o tema "violência", o grupo detevese a discutir sobre as próprias condições de trabalho. Desse modo, entendemos que falar sobre isso é também falar de violência, pois trabalhar num lugar onde inexiste espaço adequado para trabalho e escrivães insuficientes para a enorme demanda laboral é, no mínimo, mutilador, além de citar o conflito entre delegadas delineando-se um quadro tenso de trabalho.

Em campo, vimos que se tratava de um campo de forças bastante instituídas. Os funcionários que trabalhavam há mais tempo enunciavam uma fala instituída, no sentido de poucas possibilidades de mudança naquela instituição, e ínfimas expectativas com relação ao potencial transformador de seu trabalho. Ao contrário dos funcionários mais novos, que traziam falas pouco viciadas com relação à inércia "inerente" à delegacia. As falas assinalavam uma divisão entre "profissionais jovens, que ainda possuem garra para trabalhar" e os "profissionais antigos, que já desistiram”. Agenciava-se, a partir disso, um inexorável enrijecimento institucional e a produção da subjetividade no trabalho, fortemente marcada pela inércia, paralisante e fatalista.

Um dos pontos mais interessantes do trabalho foi, ao final de um dos encontros, após uma longa discussão coletiva sobre as angústias compartilhadas, o fato que um grupo, composto por psicólogas e psicólogos pressionou uma das delegadas para a convocação de uma assembléia. Na ocasião, uma série de problemas foram colocados em análise para que se produzissem mudanças na gestão do trabalho. Ainda que as discussões sobre os conflitos internos da delegacia diminuíram depois desse episódio, podemos perceber aí que nossas reuniões quinzenais funcionaram como um dispositivo instituinte que agenciou mudanças naquele contexto. Produziu-se uma reunião que foi muito além de um "muro de lamentações", pois a conversa permitiu uma atividade crítica que problematizou o modo de gestão, produzindo assim, uma linha de respiro na instituição que permitiu múltiplas instituições conversarem.

Desse modo, o dispositivo grupo promoveu os fluxos de interlocução entre os atores que fazem a cena da delegacia. Tendo em vista as diversas instituições que atravessam o 
grupo - vetores econômicos, políticos, libidinais, profissionais, e tantos outros que podemos aqui catalogar, essa linha de respiro produziu ruptura na delegacia, podendo-se dizer nos termos da análise institucional francesa, que produziram-se aí forças instituintes, que romperam com forças instituídas, linhas de força que provocam mudanças, rupturas. Apesar das rupturas, a participação do grupo permaneceu frequente, e as discussões focaram, então, questões mais individuais, tais como relacionamentos amorosos, impasses na própria história de vida dos participantes, projetos pessoais, etc.

Também neste espaço, o grupo pôde refletir sobre os casos atendidos, suas falas foram consideradas e permitiu-se a expressão de sentimentos, no que tange aos modos como fícam afetados esses corpos atravessados por testemunhar cenas bastante violentas; e a troca de experiências, de modo a favorecer a construção de novos saberes e práticas. O espaço também possibilitou diferentes olhares e abordagens e contribuiu para a integração entre diversos serviços e para a ampliação de possibilidades de atuação. Temos aí, outra linha de respiro, pois diferentes instituições e pontos de vista puderem traçar interlocuções e modificar sua prática e meio profissional.

Para se pensar o contexto da $6^{\mathrm{a}} \mathrm{DP}$, um dos conceitos úteis é o de sobreimplicação, definido como:

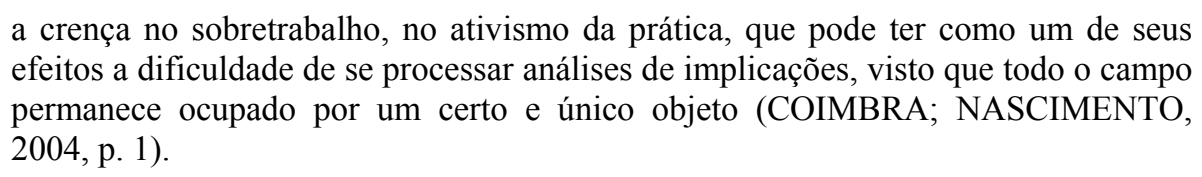

O acúmulo de tarefas e a produção de urgências são dois dispositivos que contribuem para a prática de sobreimplicação, na medida em que "impõem e naturalizam a necessidade de respostas rápidas e competentes tecnicamente, podendo estar afirmando, assim, um certo ativismo" (COIMBRA; NASCIMENTO, 2004, p. 2). Neste processo, conforme os sujeitos mergulham em um constante imperativo do fazer para dar conta das demandas, outros níveis implicados nas circunstâncias com as quais se deparam tornam-se invisíveis, de tal modo que experimentam uma generalizada frustração e culpabilização. Coimbra e Nascimento (2004) ainda destacam que

Presos nessas camisas de força, os profissionais, em muitos momentos, não dispõem de tempo para pensar e colocar em análise suas práticas. Os espaços coletivos de discussão vão se esvaziando, cada vez mais se tornam difíceis de sustentar, de serem mantidos. A falta de tempo, a urgência domina tudo e a todos, produzindo uma perda na capacidade de potencializar os encontros. As circunstâncias vividas podem trazer uma forte individualização das ações, impedindo outras relações de trabalho, outros sentidos e práticas mais coletivas ( $\mathrm{p} 7)$.

Frente a nossa proposta inicial de trabalho, umas das primeiras falas que surgiu foi: 
"Nós já estamos cansados de capacitação". Descontextualizada, esta fala poderia sinalizar "preguiça", "cansaço" ou "resistência ao trabalho grupal”. Por outro lado, ampliando o foco da análise, pode ser pensado que as propostas de "capacitação" têm efeito ambíguo, pois ao invés de melhorar o trabalho, podem intensificar a sensação de "carência; falta permanente, muitas vezes atribuída à ausência de informações, de uma formação competente" (COIMBRA; NASCIMENTO, 2004, p. 6). Dessa forma, tornou-se importante atentar para que nosso trabalho não se tornasse apenas mais uma peça em processos de desgaste já atuantes na delegacia, mas possibilitasse uma outra forma de lidar com eles.

Uma resistência a tais processos configurou-se também no momento em que o grupo se organizou para reivindicar, junto à delegada responsável, novas condições de trabalho para a delegacia. E o que poderia parecer "fracasso" dessa empreitada, o fato de o grupo não mais tocar nas questões institucionais da delegacia, um novo foco de implicações passou a ser enfatizado: as circunstâncias afetivas, individuais, da história de vida de cada qual que recortam a história de vida dos profissionais. Falar sobre amor, um tema aparentemente "banal", não configurou tanto uma "resistência a tocar em assuntos delicados" (temor inicial da equipe), mas permitiu lançar um olhar também aos processos desejantes e afetivos frequentemente encobertos - que se encontram implicados naquela instituição.

Ao invés de fechar-se acerca de uma "capacitação" abstrata e alheia às suas necessidades, o grupo abriu seu corpo para agir sobre os fluxos instituintes que o constituem, que o implicam em diferentes níveis: sejam implicados enquanto instituição, sejam as implicações afetivas e desejantes da história de vida dos profissionais.

Por fim, enfatizou-se a proposta de que cada um deixasse algum registro - livro, artigo, etc. - acerca da própria história na delegacia, no intuito de que tal escrita possa ampliar os olhares para além dos discursos corriqueiros centrados no fracasso e no desânimo, funcionando como um dispositivo potencializador da vida (GUATTARI; ROLNIK, 2005).

Embora esteja explicitada a necessidade de políticas de investimento que dêem conta da preocupante realidade em que se encontra a saúde dos profissionais da delegacia, especialmente quando há uma significativa vivência de severa violência ou mesmo cronicidade na estrutura do seu local de trabalho; e embora muito já tenha sido dito, bem como importantes iniciativas já tenham sido tomadas nessa direção - como a lei Maria da Penha, por exemplo - na prática, no dia-a-dia da $6^{\mathrm{a}}$ DP há um paradoxo frente à saúde do profissional que o mantém cativo. Cativo de um sistema econômico perverso que lhe restringe as escolhas, os sonhos e os ideais do trabalho, que lhe sequestra da complexidade das relações sociais e humanas; cativo de um sistema adoecedor com o qual se mantém familiarizado. $\mathrm{O}$ 
medo de adoecer parece colocar-se no âmbito do conflito entre sua extraordinária capacidade de adaptar-se e continuar produzindo, a qualquer custo, e o sentimento de perda de identidade profissional - confirmado pela cultura narcísica em nossa sociedade - em se ver como "fracassado" (GONÇALVEZ, 2007).

\section{Considerações Finais}

As atividades de extensão realizadas na $6^{\circ} \mathrm{DP}$ de Florianópolis possibilitaram, além de uma maior compreensão acerca dos fatores que se articulam em um contexto em que se trabalha cotidianamente com o tema da violência, uma aproximação com as dificuldades vivenciadas por uma imensa demanda de profissionais que, em geral, não têm acesso a um espaço de escuta em que possam compartilhar suas angústias se sentimentos de impotências.

Através de reuniões quinzenais com a equipe engajada nesse projeto, bem como em reuniões de supervisão e discussão teórica, pôde-se perceber como este lugar de reflexão é necessário para esses profissionais, pois ali eles compartilham sentimentos e encontram coletivamente novas estratégias para enfrentar as dificuldades das atividades de uma delegacia de polícia.

Evidenciou-se um grande sofrimento psíquico nos profissionais, cuja origem é atribuída a situações de violência vividas por esses trabalhadores. Essas formas de sofrimento podem se constituir como: sentimento de impotência, falta de confiança em si, e sentimento de perda do controle ou da capacidade de fazer frente aos constrangimentos impostos pelo trabalho. A exposição prolongada a essas condições pode gerar situações duradouras de perda de iniciativa e de passividade, por vezes, patogênicas e prejudiciais tanto para o trabalhador quanto para as instituições, sobretudo, quando a eficácia do trabalho requer um engajamento ativo deste.

Apesar do relativo distanciamento do projeto inicial, pela escolha da equipe em dar maior espaço a discussão de temas urgentes ao grupo, a proposta inicial, ao longo de todo o trabalho, nunca foi negligenciada, servindo de fio condutor das atividades. Os temas violência e gênero permearam todas as oficinas, mesmo que de forma periférica, o que não poderia ser diferente, se lembrarmos que as atividades estavam sendo realizadas com profissionais de uma delegacia de polícia na qual situações de violência e, principalmente, violência doméstica são rotineiras. 


\section{Referências}

BRASIL. Lei $\mathbf{N}^{\mathbf{0}}$ 11.340/2006. Casa Civil : Subchefia para Assuntos Jurídicos. 2006

BUTLER, J. Undoing gender. New York and London: Routledge, 2004..

COIMBRA, C. \& NASCIMENTO, M. L. Sobreimplicação: práticas de esvaziamento político? Niterói: Universidade Federal Fluminense, 2004

GONÇALVEZ, Jadete Rodrigues. O profissional de saúde em enfermaria de crianças gravemente enfermas e as implicações do cotidiano do trabalho na sua saúde / Jadete Rodrigues Gonçalves; Orientador Flávia Regina Souza Ramos. - Florianópolis, 2007.

Tese(Doutorado) - Universidade Federal de Santa Catarina. Centro de Ciências da Saúde. Programa de Pós-Graduação em Enfermagem.

GUATTARI, F. \& ROLNIK, S. Micropolíticas - Cartografias do desejo. 7 ed. revisada. Petrópolis, RJ: Vozes, 2005. 